\title{
TIMP-2 and IGFBP7 as early biomarkers of acute kidney injury after orthotopic liver transplantation
}

\author{
Schiefer J, Lichtenegger P, Stefaniak J, Krenn CG, Plöchl W, Faybik P. \\ Department of Anesthesiology and General Intensive Care Medicine, Medical University of Vienna, Austria
}

\section{Background and goal of study}

Acute kidney injury (AKI) is a frequent complication after orthotopic liver transplantation (OLT) and its early detection is of crucial importance for an appropriate management. Since the traditional kidney function parameters like serum-creatinine (s-Cr) have severe limitations concerning early detection of AKI, novel biomarkers such as TIMP-2 and IGFBP7, have been studied and shown to be superior in previous studies in critically ill patients. The aim of our study was to evaluate the predictive value of these novel biomarkers during the early perioperative period after human OLT.

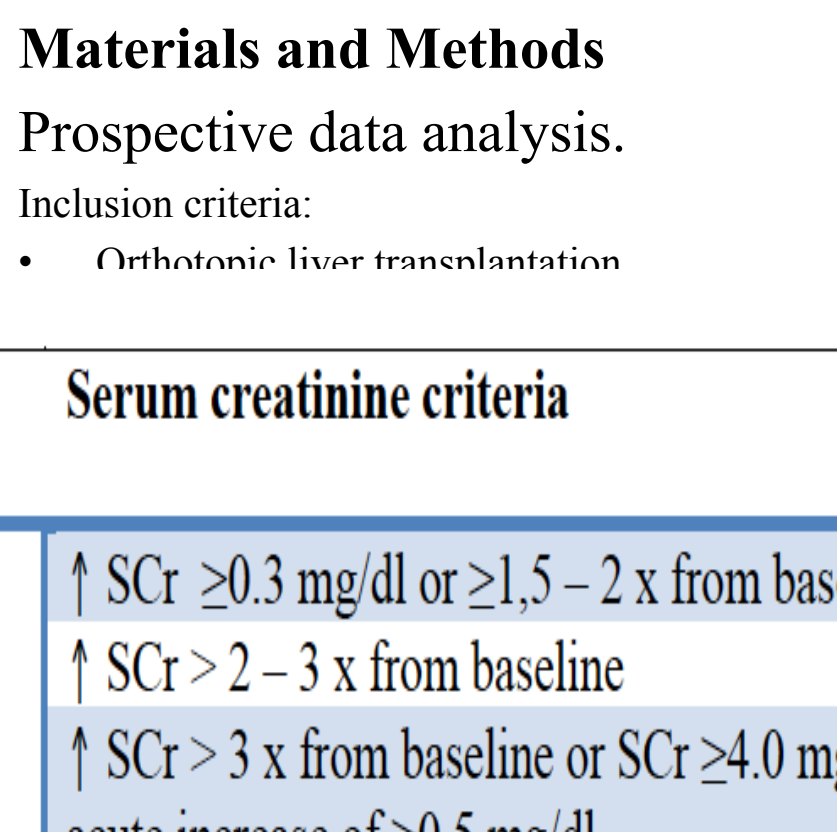

Prospective data analysis.

Inclusion criteria:

- Orthotopic liver transplantation

- Age $>18$ years

- Written informed consent

Exclusion criteria:

- Chronic kidney disease

- Preoperative renal replacement therapy

- Early termination of transplantation

- Revision surgery within 72 hours after OLT

- Age $<18$ years

- Not given informed consent

Paired urine and blood samples from patients were collected at five different time points (TP):

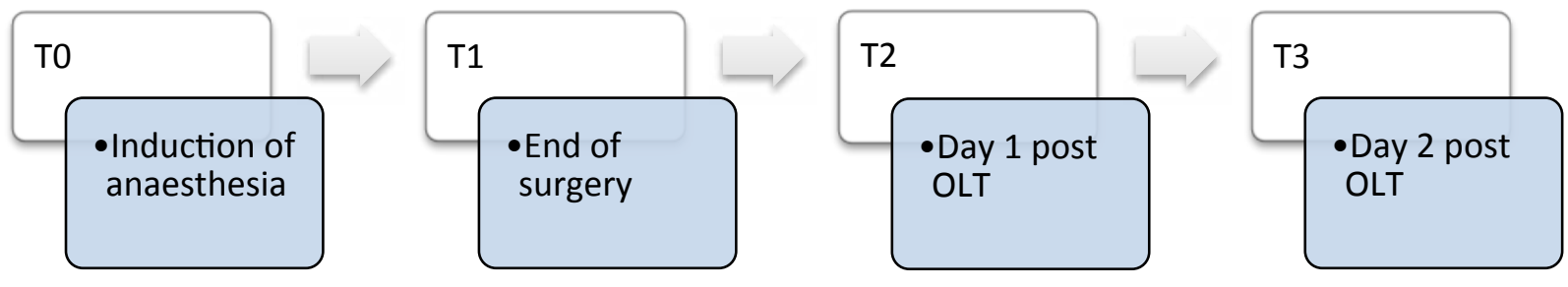

The incidence of perioperative AKI was assessed according to the Acute Kidney Injury Network (AKIN) criteria.

\begin{tabular}{|l|ll|}
\hline $\begin{array}{l}\text { AKI } \\
\text { stage }\end{array}$ & Serum creatinine criteria & Urine output criteria \\
\hline I & $\uparrow \mathrm{SCr} \geq 0.3 \mathrm{mg} / \mathrm{dl}$ or $\geq 1,5-2 \mathrm{x}$ from baseline & $<0.5 \mathrm{ml} / \mathrm{kg} />6 \mathrm{~h}$ \\
II & $\uparrow \mathrm{SCr}>2-3 \mathrm{x}$ from baseline & $<0.5 \mathrm{ml} / \mathrm{kg} / \mathrm{h}>12 \mathrm{~h}$ \\
III & $\begin{array}{l}\uparrow \mathrm{SCr}>3 \mathrm{x} \text { from baseline or } \mathrm{SCr} \geq 4.0 \mathrm{mg} / \mathrm{dl} \text { or } \\
\text { acute increase of } \geq 0.5 \mathrm{mg} / \mathrm{dl}\end{array}$ & $\begin{array}{l}<0.3 \mathrm{ml} / \mathrm{kg} / \mathrm{h} \text { for } 24 \mathrm{~h} \text { or } \\
\text { anuria for } 12 \mathrm{~h}\end{array}$ \\
\hline
\end{tabular}

The detection of urinary TIMP-2 and IGFBP7 was performed using the NephroCheck (NC) test (Astute140®Meter), an ELISA based assay, which defines the risk score for AKI.

\begin{tabular}{|c|c|}
\hline Nephrocheck ${ }^{8}$ test result & Interpretation of test result \\
\hline $\begin{array}{l}\text { Test value in the highest stratum } \\
(>2,0)\end{array}$ & High risk of AKI \\
\hline $\begin{array}{l}\text { Test value in the middle stratum }(>0,3 \text { and } \\
\leq 2,0)\end{array}$ & Intermediate risk of AKI \\
\hline Test value in the lowest stratum $(\leq 0,3)$ & Low risk of AKI \\
\hline
\end{tabular}

\section{Results and Discussion}

Forty liver transplant recipients were enrolled in this study.

Sixteen patients $(40 \%)$ developed AKI stage 2 or 3 within 48 h post OLT and $6(15 \%)$ patients were supported with renal replacement therapy.

\begin{tabular}{ll}
\hline Baseline characteristics & Mean \pm SD \\
\hline Age (years) & $56 \pm 9$ \\
BMI $\left(\mathrm{kg} / \mathrm{m}^{2}\right.$ & $26.87 \pm 4.6$ \\
Weight $(\mathrm{kg})$ & $79.9 \pm 14.3$ \\
MELD & $17.01 \pm 6.11$ \\
SCr pretransplant $(\mathrm{mg} / \mathrm{dl})$ & $0.95 \pm 0.41$ \\
AKI stage II + III & $16(40 \%)$ \\
Renal replacement therapy & $6(15 \%)$ \\
ICU stay (days) & $13 \pm 15.3$ \\
28-day mortality & $3(7.5 \%)$ \\
\hline
\end{tabular}

There was no significant difference in the receiver operating characteristics curve analysis at TP0 and TP1 between the NC test and $\mathrm{s}-\mathrm{Cr}$ in regard of development of AKI 2 or 3 within the first 48 hours post OLT. S-Cr at TP2 performed even better (AUC 0.83; CI 0.68-0.93; $\mathrm{p}=0.0001$ ) than the NC test (AUC 0.51; CI 0.34-0.67; $\mathrm{p}=0.26$ ). Only on day 2 (TP3), both, s-Cr (AUC 0.90; CI 0.76-0.97; $\mathrm{p}=0.0001$ ) and NC (AUC 0.70; CI 0.54-0.84; $\mathrm{p}=0.02$ ) predicted AKI 2 and 3.

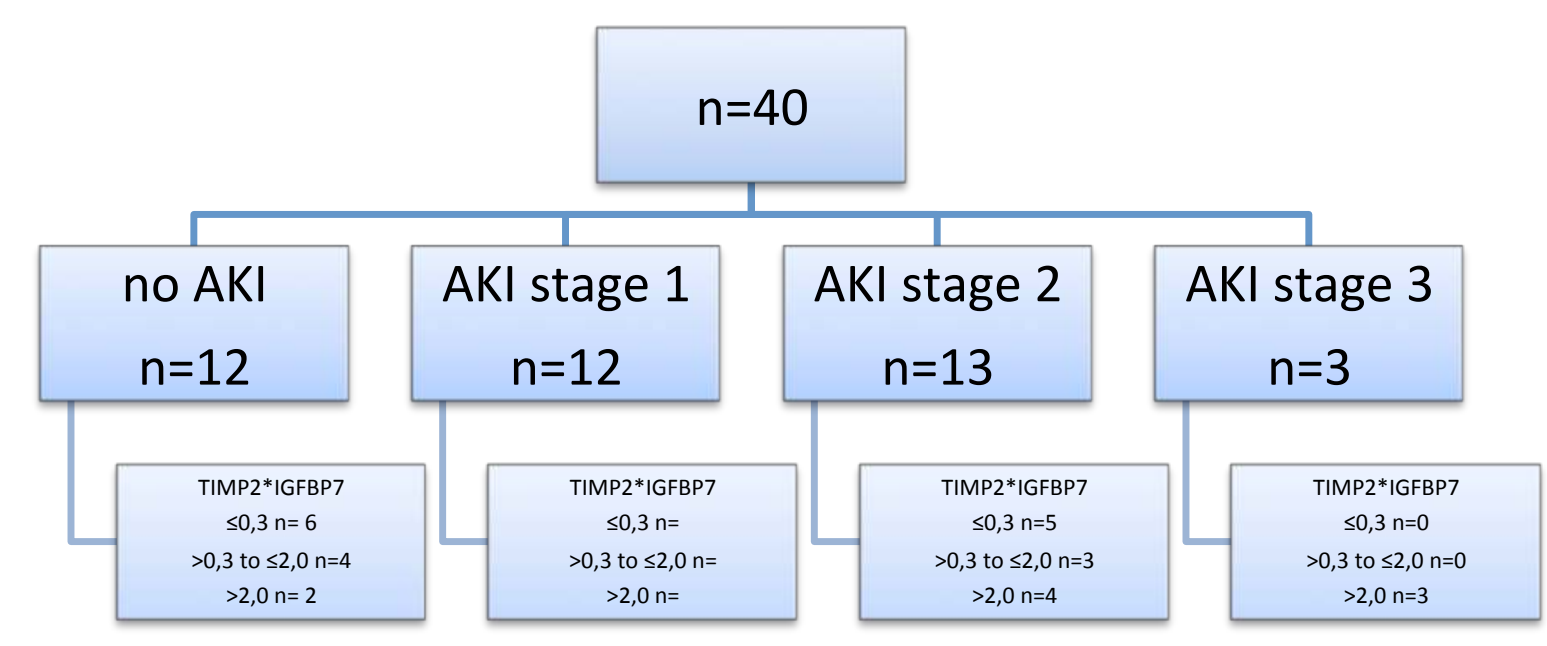

\section{Conclusion}

TIMP-2 and IGFBP7 are not superior to the traditional kidney function parameters in predicting development of perioperative AKI II and III in clinical setting of human OLT. The optimal role of these new biomarkers in the prediction, diagnosis and management of AKI requires further clarification. 